\title{
Pushing quality in health care management
}

Although the quality of medical services in the industrialized countries is very high, there are still considerable differences in outcome and thus there is a potential for improvement [5]. On the one hand, this is true for important complex diseases and procedures: it has been shown, that the adherence to guidelines and an appropriate organization of medical processes can influence outcome, for example mortality, significantly [3]. On the other hand, the rate of rare fatal events in low risk procedures can also be further reduced. The latter are often seen as a patient safety issue, but they are also a form of outcome. There is a wide consensus that the number of avoidable deaths in German hospitals might amount to between 20000 and 40000 per year. This is, for example, a multiple of the 4467 deaths from road accidents in Germany in 2008. Therefore, undoubtedly there is a necessity for further improvement of outcome in medicine.

The methods for measuring outcome have greatly improved in recent years. In many countries there is a tendency to use administrative data for routine outcome measurement at least for inpatient treatments. In most countries these data contain important medical information on diagnoses and procedures. This is especially true, if inpatient cases are reimbursed by DRG's. The information is usually available to providers as well as to payers. In the USA, the Agency for Healthcare Research and Quality (AHRQ) has developed indicators, which can be used with such data. In Germany, the Helios hospital group has developed a German set of even more detailed indicators. These have also been used as a basis for measuring quality in Switzerland and Austria [2]. In Germany the further evolvement of these indicators and their use for hospital management is an objective of the Initiative Qualitätsmedizin ( $\mathrm{IQ}^{\mathrm{M}}$ ) which currently includes more than 100 hospitals. Based on the experience of the Helios hospital group that management methods can influence outcome [4], the initiative will especially be interested in advancing peer review methods in order to improve processes where problems have been identified via outcome indicators.

Furthermore, in a joint project of the Federal Association of the largest statutory health insurance company, the AOK-Bundesverband, and the AOK Research Institute (WIdO), the Helios hospital group and the research institute Forschungsund Entwicklungsinstitut für das Sozial- und Gesundheitswesen Sachsen-Anhalt (FEISA) have developed new methods for measuring long term outcomes based on administrative data of the insurance companies [1]. Hospitals can obtain reports based on these new methods from the AOK, which provide information on their individual long-term outcome. The WIdO has also developed new aggregate indicators for better and more reliable information about outcomes even in hospitals with smaller case numbers. In diverse projects, the AOK will promote the use of outcome information for patients as well as in contracting.

The various new methods are suitable for complementing existing methods for structural quality assurance in medicine. Some process indicators used in federal quality control projects might even be replaced by a wider approach of measuring outcome instead. Structural and process related guidelines in Germany are far advanced in many cases. The introduction of new medical procedures, for example, is often accompanied by federal regulations concerning minimum requirements for their implementation. Although not recognized as such, this like some other German regulations is already a special variety of pay for performance as a reimbursable / not reimbursable (e.g. 'it's all or nothing') approach.

The new methods described above create new options for health policy. Thus the question arises in which direction the national strategies for quality in health care will proceed. Our conference will give an overview of strategies in the USA, Switzerland, Austria and Germany. In Germany, a new federal institute responsible for developing and measuring quality indicators has been commissioned by the regulating body ('Gemeinsamer Bundesausschuss'). The new concepts behind that decision will be of great interest for the audience.

Internationally the development of appropriate pay for performance (P4P) methods is one of the major topics for further progress of reimbursement methods in medicine [7]. Up to now, measuring outcome has no influence on hospital reimbursement in Germany or the neighbouring countries. Thus, quality is often seen as a marketing activity only. With respect to the severe consequences of impaired quality, however, this view is insufficient. The question is, wether quality can become a part of the reimbursement system. Therefore on the second day we will present the current experience of German statutory
T. Mansky ${ }^{1}$
M. Heberer ${ }^{2}$
J. Klauber ${ }^{3}$

Qualitätsmanagement

Bibliografie

DOI $10.1055 / \mathrm{s}-0029-1242687$

Dtsch Med Wochenschr 2009;

134: S303-S304 - (C) Georg Thieme Verlag KG Stuttgart - New York · ISSN 0012-0472

Korrespondenz

PD Dr. Thomas Mansky

Abteilungsleiter Medizinische

Entwicklung

HELIOS Kliniken

Friedrichstr. 136

10117 Berlin

Tel. 030/521 321-140

eMail thomas.mansky@

helios.kliniken.de 
health insurance companies with $\mathrm{P} 4 \mathrm{P}$ models as well as future concepts of insurance companies, the chamber of physicians and other experts. Furthermore, some international examples for P4P will be presented.

Besides institutional methods for measuring and improving quality in medicine, a major question is how to inform and educate the patient (or the insuree from the perspective of insurance companies) about understanding important medical outcome numbers. The latest obligatory quality reports in Germany have focused on the very details of hospital structures, thereby obscuring rather than illuminating the real facts of medical outcome. Therefore, we will adress the question of how to inform patients about outcome.

Our conference highlights important strategic questions from the wide area of quality measurement and management. We hope that it will contribute to innovation, information and decision making at the intersection of medical quality, hospital management and reimbursement.

Literatur

1 AOK-Bundesverband, Forschungs- und Entwicklungsinstitut für das Sozial- und $\mathrm{Ge}$ sundheitswesen Sachsen-Anhalt (FEISA), HELIOS Kliniken, Wissenschaftliches Institut $\operatorname{der}$ AOK (WIdO). Qualitätssicherung der stationären Versorgung mit Routinedaten (QSR) - Abschlussbericht. Bonn: WIdO, 2007

2 Bundesamt für Gesundheit BAG. Qualitätsindikatoren der Schweizer Akutspitäler 2006. Bern: Bundesamt für Gesundheit, 2009

3 Peterson ED et al. Association Between Hospital Process Performance and Outcomes Among Patients With Acute Coronary Syndromes. JAMA 2006; 295: 1912-1920

4 HELIOS Kliniken Gruppe. Ergebnisqualität sicher messen und aktiv verbessern - Erfahrungen. Medizinischer Jahresbericht 2006/2007. Berlin: HELIOS Kliniken, 2008

5 Kohn LT, Corigan JM, Donaldson MS. (Ed.) To err is human - Building a safer health system. Washington D.C.: Institute of medicine, 1999

6 Krause T. Randnotiz. Deutsches Ärzteblatt 2009; 106 (38): A1815

7 Porter ME, Olmsted Teisberg E. Redefining Health Care. Creating Value-Based Competition on Results. Boston: Harvard Business School Publishing, 2006 